\title{
Panel: Opportunities and Risks for Open Source Software in Industry
}

\author{
Joseph Feller $^{1}$, Björn Lundell ${ }^{2}$, Pentti Marttiin ${ }^{3}$, \\ Walt Scacchi ${ }^{4}$, and Nico Schellingerhout ${ }^{5}$ \\ 1 University College Cork, Ireland, JFeller@afis.ucc.ie, \\ 2 University of Skövde, Sweden, bjorn.lundell@his.se, \\ 3 Nokia Siemens Networks, Finland, pentti.marttiin@nsn.com, \\ 4 University of California Irvine, USA, wscacchi@uci.edu, \\ 5 Philips Medical Systems, The Netherlands, \\ nico.schellingerhout@philips.com
}

\section{Introduction}

Open Source Software (OSS) is a multi-faceted phenomenon which has become an issue of strategic importance for many commercial organisations. Stemming from an ideological issue, with emphasis on freedom and community values, we have recently seen a broader interest in the Open Source phenomenon amongst practitioners in many companies. A number of SMEs and large companies are currently exploring the potential of Open Source, and for some it has become core to their business and development activities.

Open Source is currently evolving and we have yet to see its full potential. In this panel, the goal is to stimulate discussion on the opportunities and risks to be considered with the wider adoption of Open Source systems and methods in the development of software systems in commercial organisations. In particular, the discussion will address the following issues:

- There are many different ways in which Open Source ideas can be adopted by companies, and influence the way in which companies do business and develop software systems. How can firms utilize OSS practices and tools?

- Open Source licensing has created a large commons of public software goods. How can firms create sustainable business models predicated on productizing these "commodities"?

- Open Source utilizes a legal, social and technological architecture to enable a community-based peer-production process. How can firms create sustainable business models predicated on effectively leveraging this process (either through participation or emulation)?

The panel will include short position statements by the panellists and a dialogue between them, followed by a discussion with the audience. Significant time will be allocated to an open discussion on the issues with the audience, and those attending are invited to raise their own concerns and share their own experiences. 


\section{About the Panellists}

On this international panel, the five panellists are: Joseph Feller (University College Cork), Björn Lundell (University of Skövde), Pentti Marttiin (Nokia Siemens Networks), Walt Scacchi (University of California Irvine), and Nico Schellingerhout (Philips Medical Systems). The panel will be chaired by Walt Scacchi.

Joseph Feller is a Senior Lecturer in Business Information Systems, University College Cork, Ireland. He has co-authored/edited three books on open source. He chaired the IEE/ACM workshop series on Open Source Software Engineering (20012005), served as Program Co-Chair for the Third International Conference on Open Source Systems, and is the co-chair for the Open Source and Innovation track at ECIS 2008. Dr. Feller was a principle investigator in the EU FP6 CALIBRE project, and is currently a principle investigator in Open Code, Content and Commerce (O3C) Business Models, a three year project funded by the Irish Research Council for the Humanities and Social Sciences.

Björn Lundell has been involved in a number of collaborations on open source, including the EU FP6 CALIBRE project (2004-2006) and the industrial (ITEA) research project COSI (2005-2008). He is a founding member of the IFIP Working Group 2.13 on Open Source Software, and the founding chair of Open Source Sweden, an industry association established by Swedish Open Source companies.

Pentti Marttiin is a Manager in Nokia Siemens Networks. He has been responsible for deploying OSS based Inner Source and SCM services in Nokia and Nokia Siemens Networks. He received his PhD in information systems (1998), and holds Docent position at Helsinki School of Economics, Finland. He has actively participated in EU projects (IST-MOTION, IST-Tellmaris, ITEA-MOOSE, ITEACOSI).

Walt Scacchi is senior research scientist and research faculty member in the Institute for Software Research, and also research director of the Computer Game Culture and Technology Laboratory, both at UC Irvine. He received a Ph.D. in Information and Computer Science at University of California, Irvine in 1981. His research interests include open source software development, computer game culture and technology, knowledge-based systems for modeling and simulating complex engineering and business processes, and software acquisition and electronic commerce/business. Last, he was Program Co-Chair of the 2006 Intern. Conf. on Open Source Systems, Como, Italy June 2006, and is General Chair of the 2007 Intern. Conf. on Open Source Systems, Limerick, IR, June 2007.

Nico Schellingerhout is a software team leader and responsible for the InnerSource initiative in Philips Healthcare. He is a task leader in ITEA COSI and has been involved in System Simulation and Software architectures research for over 10 years. He received his training in Computational Physics at the University of Groningen (M.Sc. 1988, Ph.D. 1995). His recent research interest is collaboration of distributed teams and the application of OSS practices in a corporate setting. 